\title{
AVALIAÇÃO DO CONHECIMENTO E OPINIÃO DOS PACIENTES SOBRE DOAÇÃO E TRANSPLANTE DE ÓRGÃOS EM UM CENTRO DE SAÚDE EM BELÉM-PA
}

\author{
Assessment of patient's knowledge and opinion on organ donation and transplantation in a \\ Brazilian Health Center
}

Thiago Barbosa Gonçalves, Renan Kleber Costa Teixeira, Victor Seiji Nascimento Hosoume e José Antonio Cordero da Silva

\section{RESUMO}

Objetivo: Avaliar o conhecimento e a opinião de pacientes do Centro de Saúde Escola do Marco (CSE-Marco), em Belém do Pará, sobre doação e transplante de órgãos. Método: Trata-se de estudo transversal observacional. Foi aplicado um questionário padronizado aos pacientes cadastrados no CSE-Marco contendo perguntas sobre doação e transplante de órgãos e dados sócio-demográficos. Resultados: Foram entrevistadas 136 pessoas, sendo a maioria dos pesquisados do sexo feminino, com média de idade de 39 anos, solteiros, possuindo ensino fundamental e católicos. A maior parte dos entrevistados era a favor da doação de órgãos. Um número um pouco menor de pesquisados doaria seus órgãos; desses, poucos informaram seu desejo aos familiares. A maioria da amostra acredita que há venda de órgãos no Brasil e que pessoas ricas têm mais chances de receber um órgão. Os pesquisados apresentam baixo conhecimento sobre os órgãos que podem ser transplantados entre seres humanos. Os mais jovens estão mais propensos à doação de órgãos, e grande parte das mulheres que normalmente são responsáveis pela decisão de doar órgãos de parentes não autorizariam o transplante. Conclusão: Apesar da maioria da população afirmar que é favorável à doação de órgãos, poucos potenciais doadores convertem-se em doadores efetivos. Isso se deve ao desconhecimento da população acerca da doação e transplante de órgãos e ao fato da maioria das pessoas não informar aos familiares sua vontade de doar órgãos.

Descritores: Transplante, Opinião Pública, Doação de Órgão

Instituição:

Departamento do Núcleo de Pesquisa em Bioética da Universidade do Estado do Pará - Belém /PA - Brasil

\section{Correspondência:}

Thiago Barbosa Gonçalves

Tv. Dom Romualdo Coelho, 722 / 2102 - CEP 66055-190 - Belém/PA

Fax: (91) 3241-9562

E-mail: tbgow@hotmail.com

\section{INTRODUÇÃO}

O aprimoramento das técnicas cirúrgicas e o aumento da qualidade de vida dos pacientes transplantados fizeram com que as indicações para transplantes de órgãos e o número de pacientes à procura dessa terapia crescessem significativamente nas duas últimas décadas. ${ }^{1}$

Entretanto, a demanda para transplantes ainda é muito alta frente à disponibilidade de órgãos. Em diversos países como Estados Unidos e Brasil, a falta de órgãos torna expressivos a fila de espera e o número de pacientes que morrem enquanto aguardam o transplante. ${ }^{2}$

Devido à carência de órgãos para transplantes, estudos têm sido realizados e diversas propostas vêm sendo elaboradas para aumentar a captação de órgãos. A baixa percentagem de doadores é citada como fator limitante no incremento do número de transplantes. ${ }^{2-6}$

No Brasil não há muitos dados a respeito da opinião geral da população acerca da doação de órgãos. ${ }^{7,8}$ Existiam mais de 36 mil pessoas aguardando transplante de órgãos ou tecidos no Brasil em 2011; ${ }^{9}$ entretanto, o número de transplantes realizados atualmente é muito pequeno; foram realizados apenas 3.278 transplantes de órgãos no primeiro semestre de $2011 .{ }^{10}$ 
Dados da Associação Brasileira de Transplante de Órgãos sugerem que metade das famílias de potenciais doadores recusa a doação de órgãos. ${ }^{7}$ Os motivos dessa recusa ainda não estão bem elucidados. Dessa forma, o objetivo deste estudo é avaliar o conhecimento e a opinião dos pacientes do Centro de Saúde Escola do Marco (CSE) em Belém do Pará sobre doação e transplante de órgãos.

\section{MÉTODO}

Todos os pacientes foram pesquisados segundo os preceitos da Declaração de Helsinque e do Código de Nuremberg. A pesquisa só foi iniciada após aprovação pelo Comitê de Ética em Pesquisa da Universidade do Estado do Pará (CEP/UEPA).

Este trabalho caracteriza-se como prospectivo, transversal e observacional, onde foi aplicado um questionário padronizado a 136 pacientes provenientes do Centro de Saúde Escola do Marco (CSE-Marco). Antes da aplicação desses questionários foi apresentado o Termo de Consentimento Livre e Esclarecido (TCLE) a cada paciente, sendo necessário assiná-lo para poder participar da pesquisa. Esse questionário apresentava questões relativas ao conhecimento e à opinião sobre doação e transplante de órgãos, além de dados sócio-demográficos.

Os critérios de inclusão foram: ser paciente cadastrado no CSEMarco, ser de um dos sexos e maior de 18 anos, tendo como critérios de exclusão ser menor de idade, ser acompanhante de paciente e não aceitar assinar o TCLE.

Foram utilizados os softwares Excel 2007 para a confecção de dados e tabelas e BIOESTAT 5.0 para análise estatística quantitativa, utilizando-se para isso o teste qui-quadrado $(p<0,05)$. De acordo com a natureza das variáveis, foi aplicada análise estatística descritiva, tendo sido informados os valores percentuais dos dados analisados.

\section{RESULTADOS}

Foram entrevistados 136 pacientes do CSE-Marco; destes, 93 $(68,4 \%)$ eram do sexo feminino e $43(31,6 \%)$ do masculino; a idade média foi de $39 \pm 13,66$ anos, sendo a idade mínima 18 anos e a máxima, 81 anos. O estado civil da maioria $(46,3 \%)$ dos entrevistados era solteiro, seguido de casado (39,7\%), havendo ainda 11 pacientes $(8 \%)$ viúvos e oito $(6 \%)$ separados. Quanto à escolaridade, $57,4 \%$ possuíam ensino médio completo, 27,9\% tinham ensino fundamental, $14 \%$ ensino superior e apenas uma pessoa $(0,7 \%)$ era analfabeta. Já em relação à religiosidade, $54,4 \%$ eram católicos, 40,4\% eram evangélicos e os demais $(5,2 \%)$ professavam outras religiões.

Quando se questionou sobre a opinião acerca da doação de órgãos, a maioria $(84,6 \%)$ declarou-se favorável e 15,5\%, desfavoráveis. Quando a pergunta foi se os pesquisados aceitariam receber um órgão caso precisassem, 93,5\% responderam que sim e apenas $6,5 \%$ disseram que não. Houve diferença estatística significativa em relação à idade, ou seja, pessoas com 18 a 22 anos são mais propensas à doação de órgãos $(\mathrm{p}<0,05)$. Dessa faixa etária, 92,5\% são favoráveis aos transplantes.

Já em relação a doar seus próprios órgãos ou parte desses em vida, $79,4 \%$ dos entrevistados afirmaram que aceitariam doar e $20,6 \%$ não aceitariam essa hipótese. No entanto, quando questionados sobre a doação de órgãos após a morte, $72 \%$ eram a favor e $28 \%$ contra.
Dentre os pesquisados que afirmaram não doar seus órgãos após a morte, $54 \%$ disseram possuir essa opinião devido ao medo de serem diagnosticados em morte encefálica mesmo estando vivo; 23\% afirmaram que não doariam devido a motivos religiosos e a mesma percentagem (23\%) tinha essa opinião por acreditar que há corrupção no sistema de doação de órgãos.

Quando questionados se haveria venda de órgãos no Brasil, 64\% responderam que sim e $36 \%$ responderam que não existe comércio ilegal de órgãos neste país. Para $67,6 \%$ dos pesquisados, os ricos possuem privilégios na fila de espera para receber um órgão, enquanto que para 30,9\% não há relação entre a situação sócioeconômica e privilégios na fila de transplantes e a grande minoria $(1,5 \%)$ acha que os pobres possuem preferência nessa fila. Além disso, grande parte da população pesquisada (85,3\%) acredita que o médico poderia equivocar-se ao dar diagnóstico de morte encefálica e o paciente ainda estar vivo.

Dos pacientes que afirmaram doar seus órgãos após a morte, apenas $40,8 \%$ responderam que informaram aos familiares sua vontade de doar órgãos e a maioria $(59,2 \%)$ disse que não comentou o assunto com seus parentes.

Quando as perguntas foram sobre conhecimento da população acerca da viabilidade de transplantar um determinado órgão, os pesquisados mostraram desconhecimento, como pode ser observado na Figura 1. Além disso, 70\% acreditavam que a espera na fila dos transplantes é de mais de três anos.

Ao relacionar o sexo com a autorização da doação dos órgãos de familiar de $1^{0}$ grau encontrou-se uma relação estatisticamente significante $(\mathrm{p}<0,05)$ : apenas $61(65,6 \%)$ mulheres, que normalmente são responsáveis pela decisão, autorizariam a doação dos órgãos de um parente e $32(34,4 \%)$ mulheres não autorizariam, enquanto que a grande maioria $(86 \%)$ dos homens autorizaria o transplante.

\section{DISCUSSÃO}

Atualmente, a grande dificuldade na realização de transplante de órgãos deixou de ser a técnica cirúrgica complexa e passou a ser a dificuldade de conseguir órgãos viáveis para o transplante, sendo que essa dificuldade é ampliada pela recusa familiar, onde, em vários casos, os órgãos poderiam ser utilizados caso a família autorizasse a doação. ${ }^{11}$

Ao analisar a população estudada, percebe-se que a maioria das pessoas diz ser favorável à doação de órgãos. No entanto, o número de pesquisados que disseram aceitar receber um órgão é substancialmente maior. Esse fato demonstra certo individualismo das pessoas pesquisadas.

Quando se compara o número de pessoas que afirmaram doar seus órgãos em vida com aqueles que afirmaram doar inclusive após a morte, percebe-se que há uma diferença considerável na percentagem, sendo que o número daqueles que doariam após a morte é consideravelmente menor. Isso demonstra o descrédito no sistema de transplantes e nos critérios de morte encefálica difundidos pelo Conselho Federal de Medicina ${ }^{12}$ entre a classe médica; portanto, há necessidade de que tais informações sejam mais difundidas também no âmbito leigo.

Esse fato é comprovado, observando-se que a grande maioria da população pesquisada acredita que o médico poderia se equivocar ao dar diagnóstico de morte encefálica e o paciente ainda estar vivo. Além disso, entre os entrevistados que afirmaram não doar 
seus órgãos, grande parcela deles afirma que tem essa opinião por medo de receber diagnóstico de morte encefálica estando ainda vivo. Tal achado foi semelhante ao de Coelho et al ${ }^{13}$ e Bendassolli, 14 mostrando que o medo do diagnóstico equivocado da morte encefálica é um fator dificultante da doação de órgãos.

Além disso, a falta de credibilidade no sistema de transplantes por parte dos entrevistados pode ser evidenciada pelo fato de que uma parcela dos que são contra a doação citam a corrupção no sistema de doação de órgãos, como motivo para serem contrários. Corroborando com esse dado, parte da população pesquisada afirmou que há venda de órgãos no Brasil e que os ricos possuem prioridade em relação aos pobres na fila de transplantes.

Ainda deve ser percebido que mesmo entre aqueles que são a favor da doação de seus órgãos, menos de dois terços da amostra informaram sua vontade aos familiares. Esse é um dado preocupante, já que no Brasil desde 2001 vigora o consentimento informado, ou seja, a decisão da doação de órgãos é realizada pelos parentes mais próximos do potencial doador e não pela decisão em vida do paciente, mesmo que expressa em documento de identidade. ${ }^{12} \mathrm{~A}$ falta do conhecimento da opinião do potencial doador por parte da família é gerada pela ausência de políticas públicas que favoreçam a discussão no seio familiar e a valorização da doação de órgãos pela população leiga. ${ }^{11,13}$

Essa ausência de campanhas públicas sobre doação de órgãos reflete o desconhecimento da população sobre aspectos dos transplantes apresentados nesta pesquisa como tempo na fila de espera e quais órgãos podem ou não ser transplantados. Para todos os órgãos citados, muitas pessoas afirmaram não saber qual órgão específico pode ou não ser doado. Uma boa parcela dos entrevistados afirmou erroneamente que o cérebro pode ser transplantado.

Deve-se incentivar a realização de campanhas sobre a doação de órgãos, visto que em pesquisa conduzida por Barcelos ${ }^{14}$ concluiuse que quando o debate sobre doação de órgãos está em pauta na sociedade, as taxas de doação são em torno de $63 \%$, e na ausência de debates sobre esse tema, esse valor cai para $21 \%$, mostrando a importância das campanhas públicas acerca de doação de órgãos.

As realizações de medidas públicas para incentivar a doação de órgãos são importantes para a população mais jovem de 18 a 22 anos, que tem melhor conhecimento sobre o valor da doação de órgãos e maior acesso a campanhas publicitárias, apresentando opinião mais favorável à doação do que os outros participantes da pesquisa, mostrando que a educação e o conhecimento sobre a importância da doação de órgãos é o fator que mais contribui para a aceitação da doação, sendo pouco influenciada pela condição de renda, como visto no estudo de Bendassolli. ${ }^{15}$

Outros pesquisadores mostraram que as campanhas públicas de doação de órgãos e tecidos são de grande valia para incentivar a doação: ${ }^{16}$ estudando a influência das campanhas de marketing na doação de córneas, eles concluíram que ao final da pesquisa, 82,9\% das doações eram decorrência das propagandas realizadas anteriormente.

Um dado acalentador que ressalta o poder das campanhas foi o alto índice de pessoas aceitando que os órgãos e tecidos transplantados no Estado do Pará - rim e córnea - podem ser de fato transplantados, demonstrando que a proximidade da população com esses tipos de transplantes e a maior difusão de campanhas sobre a doação desses órgãos e tecidos no Estado deram resultados positivos.

Esse dado contrasta com um dos mais preocupantes da pesquisa: quando se relacionou o sexo com a autorização da doação dos órgãos de um familiar de $1^{\circ}$ grau $(\mathrm{p}<0,05)$ foi visto que as mulheres - que normalmente vivem mais que os homens e, portanto, são na maioria das vezes responsáveis pela decisão da doação de órgãos de familiares - são menos propensas a autorizar a doação, quando comparadas aos homens. Atribui-se esse dado ao fato de que há poucas campanhas sensibilizadoras sobre o tema ${ }^{17}$ e somando essa desconfiança das mulheres acerca do sistema de doação, chega-se a um menor índice de autorização de doação órgãos dos potenciais doadores por parte das pesquisadas do sexo feminino.

\section{CONCLUSÃO}

Apesar da maioria da população afirmar ser favorável à doação de órgãos, poucos potenciais doadores convertem-se em doadores efetivos; isso se deve a uma grande diversidade de fatores, incluindo como visto neste estudo o desconhecimento da população acerca da doação e transplante de órgãos e ao fato da maioria das pessoas não informar aos familiares sua vontade de doar órgãos, o que é resultado das poucas campanhas esclarecedoras sobre esse assunto e do pouco acesso a informações sobre esse tema.

\section{ABSTRACT}

Purpose: To assess the knowledge and opinion of patients in a Brazilian Health Center in Belém on organ donation and transplantation. Method: This is an observational cross-sectional study. It was administered a standardized questionnaire to patients enrolled in the Health Center. It contained questions about the organs donation and transplantation and socio-demographic data. Results: It was interviewed 136 people being most of respondents female with mean age 39, unmarried, with elementary school, and Catholics. Most of respondents were in favor of the organ donation. A slightly smaller amount of respondents would donate their organs; from that group, few people reported their opinion to their families. Most of the sampling believes there is trading of organs in Brazil, and rich people are more likely to receive an organ. Respondents have a low level of awareness on the organs which can be transplanted in humans. Younger people are more likely to donate organs, and most women who are usually responsible by the decision of donating organs of relatives would not allow the transplant. Conclusion: Although the majority of people asserts to be supportive to the organs donation, few potential donors become actual donors, due to people ignoring things on the organ donation and transplantation and the fact that most of people do not inform their family on their willingness to donate organs.

Keywords: Transplantation, Public Opinion, Directed Tissue Donation 


\section{REFERÊNCIAS}

1- Lucey MR. Liver transplantation for alcoholic liver disease: Past, present, and future. Liver Transpl. 2007;26:190-2.

2- Taylor R, Franck LS, Gibson F, Dhawan A. A critical review of the healthrelated quality of life of children and adolescents after liver transplantation. Liver Transpl. 2005;11:7-9.

3- Chan HM, Cheung GM, Yip AK. Selection criteria for recipients of scarce donor livers: a public opinion survey in Hong Kong. Hong Kong Med J. 2006;12:40-6.

4- Pereira WA, Arruda DMR, Mendonça RCF, Haddad JPA. Opinião dos profissionais da saúde em relação à doação de órgãos e tecidos para transplante no ano de 2009 - Santa Casa de Belo Horizonte/MG. J Bras Transpl. 2009;12:1138-40

5- Oliveira-Júnior RE, Saldanha BO, Oliveira APP, Santos EA, Oliveira MP, Pereira WA, Filho CS. Conhecimento sobre morte encefálica e doação de órgão entre estudantes de medicina de Belo Horizonte. J Bras Transpl. 2009; 12:1148-52

6- Rodrigues TK, Junior AA. Estimativa do número de possíveis doadores de órgãos no estado de Sergipe no ano de 2007. J Bras Transpl. 2010; 13:1329-92

7- Coelho JCU, Fontan RS, Pereira JC, Wiederkehr JC, Campos ACL, Zeni Neto C. Doação de órgãos: opinião e o conhecimento de médicos intensivistas da cidade Curitiba. Rev Assoc Med Bras. 1994;40:36-8.

8- DeMoraes MW, Gallani MCBJ, Meneghin P. Crenças que influenciam adolescentes na doação de Órgãos. Rev Esc Enferm USP. 2006;40:484-92.
9- Portal.saude.gov.br/portal/arquivos/pdf/listadeespera_200411 [homepage na internet]. Brasil. Lista da espera de transplante de órgãos 2010. 2011. [acesso em 2011 Abr 12].

10- Associação Brasileira de Transplantes de Órgãos. Registro Brasileiro de Transplantes 2011;17(2):7-24.

11- Salada MLA. A experiência de doar órgãos na visão de familiares de doadores. J Bras Nefrol 2001;23(3):143-51

12- Brasil. Lei Federal No 10.211/01. Disponível em: <http://www.ufrgs.br/bioetica/lei0211.htm > Acessado em 20 de setembro de 2011.

13- Coelho JCU, Cilião C, Parolin MB, Freitas ACT, Gama Filho OP, Saad DT, et al. Opinião e conhecimento da população da cidade de Curitiba sobre doação e transplante de órgãos. Rev Assoc Med Bras 2007;53(5):421-5

14- Bendassolli PF. Percepção do Corpo, Medo da Morte, Religião e Doação de Órgãos. Psicologia: Reflexão e Crítica. 2001;14(1):225-40

15- Barcellos FC. Intenção de doar órgãos em uma população adulta. [Tese - mestrado] Pelotas (RS): Universidade Federal de Pelotas - Faculdade de Medicina. 2003

16- Farias RJM, Souza LB. Impacto do marketing dos processos de divulgação nas doações de córneas a um banco de tecidos oculares humanos e avaliação do perfil socioeconômico de seus doadores. Arq. Bras. Oftalmol. 2008;71(1):28-33

17- Batista CR, Kusterer LEFL. Conhecimento de estudantes de medicina sobre doação e transplantes de órgãos. J Bras Transpl. 2010;13:1281-328 